\title{
ИНТЕРРОГАТИВНОЕ ВЫСКАЗЫВАНИЕ КАК СРЕДСТВО СВЯЗНОСТИ ХУДОЖЕСТВЕННОГО ТЕКСТА (НА МАТЕРИАЛЕ POMAНА Г.СВИФТА «WATERLAND»)
}

\section{INTERROGATIVE UTTERANCE AS A COHESIVE FACTOR IN "WATERLAND" BY G. SWIFT}

\section{K. Gladkova}

Summary: The article is focused on the problem of relation of two linguistic categories, interrogativity and text cohesion, in a literary text. The aim of the research is to study the role of interrogative utterances as a cohesive factor in «Waterland» by G. Swift. The author provides an analysis of interpretations of the key notions of the research, such as "question», «interrogative sentence», «question - response unity», «interrogative utterance». Interrogative utterance is considered to be a factor of text cohesion by its definition, as it presents the unity of question and an answer. The author assumes that formally developed explicit interrogative utterances contribute to formal cohesion, while implicitness and syntactical incompleteness stimulate implicit type of cohesion on the conceptual level of the novel. The analysis of the macrolevel of the novel demonstrates that interrogative utterances function in the plot development; facilitate semantical cohesion between chapters, form thematical and conceptual unity of the literary text, and serve to promote the unity of imaginary.

Keywords: interrogative utterance, question, answer, text cohesion, literary text, G. Swift.
Категория интеррогативности исследована в науке с разных позиций. Существует множество работ, посвященных изучению логико-философских истоков вопросительности, ее роли в гуманитарных и компьютерных дисциплинах. В лингвистике освещаются проблемы семантики, функций, а также своеобразия языкового представления категории интеррогативности в текстах разных функциональных стилей. Актуальным является изучение взаимосвязи интеррогативности с категорией связности текста, которое позволяет более детально исследовать природу текстообразования. В настоящей статье мы проанализируем один из аспектов взаимодействия двух фундаментальных категорий лингвистики, а именно роль интеррогативного высказывания в формировании связности художественного текста.

В первую очередь обратимся к определению ключевого понятия. Проблема вопросительного предложения в лингвистике исследуется с точки зрения различных

\author{
Гладкова Катерина Юрьевна \\ Пермский государственный национальный \\ исследовательский университет \\ Katerina_G_L@mail.ru
}

Аннотация: В настоящей статье проанализирован один из аспектов взаимодействия категорий интеррогативности и связности в художественном тексте. Целью статьи является изучение роли интеррогативного высказывания в формировании связности художественного текста на материале романа Г. Свифта «Waterland». Автор дает обзор трактовок ключевых понятий исследования, а именно: понятия «вопрос», «вопросительное предложение», «вопросно-ответный комплекс», «интеррогативное высказывание». Это высказывание по определению способствует связности текста, поскольку уже на уровне микроконтекста представляет собой взаимосвязь вопроса и ответа, а на уровне макроконтекста способствует формированию глав, сюжетных и тематических линий, а также событийному, тематическому и образному единству романа. Такие характеристики интеррогативного высказывания, как эксплицированность/имплицированность, развернутость/сжатость непосредственно влияют на актуализацию текстовых связей, как на поверхностном, так и на глубинном уровне.

Ключевые слова: интеррогативное высказывание, вопрос, ответ, связность, художественный текст, Г. Свифт.

направлений. В грамматике, главным образом, изучают специфику языковой формы вопросительных предложений, которые отличаются от других типов предложения формальными маркерами: интонационным контуром, инвертированным порядком слов, наличием вопросительных слов $[4,16,22]$. Семантика и теория речевых актов освещают проблему неоднородности плана содержания вопросов и разнообразие реализуемых ими функций $[2,8,12,13,14,18]$. Стилистика также исследует проблему несоответствия плана выражения и плана содержания вопросительного предложения, что отражается в теории функционально-стилистического сдвига, при котором вопросительная семантика выражается невопросительной формой и наоборот $[1,6,19]$.

С позиций функциональной стилистики изучают вопросы в аспекте их роли в текстах различных функциональных стилей. В научном тексте, например, вопрос стимулирует рефлексию с целью переосмысления старого 
знания и выведения нового знания [7]. Вопросительные предложения и вопросно-ответные комплексы способствуют реализации категории диалогичности и экспрессивности научного текста [3, с. 57; 10, с. 302, 306-307]. В текстах публицистического функционального стиля вопросы являются одним из средств репрезентации экспрессивности и апеллятивности текста, а также служат обращению читательского внимания к затрагиваемой проблеме [10, с. 359-360]. В текстах официально-делового стиля вопрос необходим для реализации стилевой черты точности, не допускающей инотолкования [10, с. 335]. В теории художественного текста разрабатывается понятие лирического вопроса, обладающего рядом функций: познавательной, эстетической, коммуникативной, модальной и др. Лирические вопросы, в целом, служат реализации индивидуально-авторской эстетической концепции [9].

В функциональной стилистике с позиций логико-семантического подхода разрабатывается понятие «вопросно-ответного хода» как разновидности конструктивного приема, в основе которой лежит принцип последовательного развертывания смыслового единства. Под конструктивным приемом понимают вид семантических отношений между основными смысловыми элементами логического единства, который служит стилистической выразительности и экспрессивности текста. В свою очередь логическое единство определяется как структурная единица речи и мышления, представляющая собой объединение нескольких суждений [20, с. 175-177]. Таким образом, понятие «вопросно-ответный ход» восходит к понятию «логическое единство» и может быть охарактеризовано в качестве единицы речемыслительной деятельности человека, подразумевающей тесную взаимосвязь между вопросными и ответными высказываниями, объединенными общей семантикой. В лингвистике также существует понятие «вопросно-ответного комплекса», которое трактуется как структурно-семантическое единство, состоящее минимально из двух предложений и являющееся одним из способов репрезентации категории диалогичности текста, речи и мышления в целом [20, с. 51]. Полагают, что вопросноответные комплексы можно считать разновидностью логического единства, а именно логико-языковым образованием, выполняющим познавательную и коммуникативную функции [17]. Кроме того, исследуется экспрессивный и эстетический потенциал вопросно-ответных комплексов в публицистике и в художественном тексте $[5,15]$, а также их роль в экспликации рассуждения, формулировании гипотезы и авторской концепции в текстах научного функционального стиля [10, с. 306; 20, с. 51].

В рамках данного исследования мы придерживаемся понятия «интеррогативное высказывание», которое разрабатывается в концепции А.В. Логинова и трактуется как структурообразующий и функционально-значимый компонент категории интеррогативности, выражающий потребность в информации о чем-либо [11, с. 3-4]. Целью настоящей статьи является изучение роли интеррогативных высказываний в образовании связности художественного текста на материале романа Г. Свифта «Waterland».

Прежде чем перейти к анализу языкового материала, обратимся к биографии и творчеству Г. Свифта с целью понимания философско-эстетических взглядов автора и художественного своеобразия изучаемого произведения. Г. Свифт (р. 1949) - современный британский писатель, автор множества известных произведений, в числе которых романы «The Sweet-Shop Owner» (1980), «Shuttlecock» (1981), «Waterland» (1983), «Last Orders» (1996), «Wish You Were Here» (2011), сборники рассказов «Learning To Swim and Other Stories» (1982), «England and Other Stories» (2014), критических эссе, стихотворений, воспоминаний «Making an Elephant: Writing from Within» (2009). Творчеству писателя присущи такие черты, как глубокий психологизм, осмысление острых морально-нравственных проблем и философских вопросов, исследование тем мировой и частной истории, семьи, времени [24, 25, $26,27,28]$. Полагают, что роман «Waterland» («Водоземье», 1983) наиболее глубоко разрабатывает темы мировой и семейной истории, времени, прошлого, проблему цикличности истории, соотношения правды и вымысла и т.д. [23, с. 207].

В центре повествования - семейная драма школьного учителя истории Тома Крика. Повествование является сложно организованным: в рассказ главного героя о событиях своей жизни вплетаются события мировой истории, воспоминания, рассуждения о серьезных морально-нравственных проблемах и философских категориях. В силу своей многомерности и многоаспектности повествование романа характеризуют как ризоматическое письмо, наиболее похожее на пример гипертекста в интернете, в котором различные сюжетные линии и ассоциативные ряды связаны в единую сеть. Рассказчик, находясь в центре повествования, является и своеобразным творцом той истории, которую он предлагает читателю [27, с. 115]. Своеобразие композиционной организации произведения, характеризующейся нелинейностью и ретроспекцией, способствует реализации проблемы цикличности жизни, зацикленности на прошлом [23]. Осмысление героями произведения глубоких нравственных вопросов, проблема поиска причины в прошлом и осознание невозможности его изменить составляет, на наш взгляд, идейно-эмотивную основу романа. Вопрошание и поиск причины являются ключевыми смысловыми линиями романа «Waterland», обусловливающими сложную сюжетно-композиционную организацию произведения. 
Обратимся к роли интеррогативных высказываний в формировании связности в романе «Waterland». Мы полагаем, что интеррогативное высказывание способствует связности текста уже на уровне микроконтекста, поскольку представляет собой взаимосвязь вопроса и ответа. Анализ интеррогативных высказываний романа позволил выявить их разновидности и роль в формировании связности текста. По параметру эксплицированности вопроса/ответа были выявлены интеррогативные высказывания с эксплицированным и частично эксплицированным вопросом/ответом, а также с имплицированным ответом. По параметру развернутости вопроса/ответа, в романе представлены интеррогативные высказывания с развернутым и сжатым вопросом/ ответом и их комбинации. По параметру контактности/ дистанцированности вопроса и ответа были выявлены интеррогативные высказывания с ответом в контактной и дистанцированной позиции. Рассмотрим пример интеррогативного высказывания с эксплицированными вопросом и ответом в контактной позиции:

How did the Cricks outwit reality? - By telling stories [29, c. 25].

Анализируемое интеррогативное высказывание демонстрирует непосредственную контактную связи между вопросом и ответом. Во-первых, предложения объединены общей семантикой нереального, сказочного, репрезентированной существительными «reality», «stories» и глаголом «outwit». Во-вторых, вопросительное наречие «how» и предлог «by», с которого начинается ответ, выражают общую семантику образа действия. В-третьих, ответ характеризуется сжатостью и емкостью, что достигается посредством использования эллипса, актуализирующего непосредственную связь между вопросом и ответом, а именно тесную зависимость ответа от вопроса, поскольку вне ближайшего контекста ответ был бы бессмысленным. Таким образом, на микроуровне рассматриваемое интеррогативное высказывание выражает законченную авторскую мысль и характеризуется общностью семантики и синтаксическим единством. Кроме того, оно способствует формированию связности текста в пределах макроуровня произведения. С одной стороны, рассматриваемое интеррогативное высказывание стимулирует авторские рассуждения относительно семьи Крик, их способности осмыслять реальность посредством придумывания и рассказывания сказок и историй, что формирует часть главы «About the Fens».

На лексико-семантическом уровне тема сказочности, вымышленности репрезентирована в данной главе, например, следующими словами и сочетаниями: «superstitious», «stories», «strange», «history», «imaginary», «supernatural», «legends», «counter-stories», «rites», «fairy-tale land» и др. С другой стороны, поскольку композиционно рассматриваемый контекст расположен в начале произведения, он актуализирует антитезы «история - сказка», «вымысел - реальность», тему семьи, сюжетную линию, связанную с развитием Фенов, которые являются смысловой основой всего произведения. Тема сказочности, репрезентированная в данном интеррогативном высказывании, не только является одной из центральных тем романа, но и играет ключевую роль в композиционной и повествовательной организации произведения, поскольку повествование ведется от лица человека, рассказывающего истории о своей жизни.

В ходе анализа материала нами была выявлена разновидность интеррогативного высказывания, представляющего собой комбинацию вопроса и развернутого ответа в контактной позиции. Проанализируем следующий пример:

What do you do when reality is an empty space? - You can make things happen - and conjure up, with all the risks, a little token urgency; you can drink and be merry and forget what your sober mind tells you. Or, like the Cricks who out of their watery toils could always dredge up a tale or two, you can tell stories [29, c. 67].

В данном случае наблюдается параллельный вид связи между вопросом и ответом. Вопрос сформулирован достаточно четко и требует предложения конкретных решений, советов, действий, что, во-первых, репрезентировано в вопросительном наречии «what», предполагающем конкретику и точность, во-вторых, в настоящем времени глаголов, актуализирующем как значение непосредственно настоящего времени, так и значение настоящего вневременного. В ответе, представляющем собой совокупность сложных, развернутых предложений с рядами однородных членов и вставными конструкциями, даются варианты решения проблемы, заявленной в вопросе. Грамматическая связь внутри вопросно-ответного контекста достигается посредством использования настоящего времени глаголов (do, can), что позволяет сделать вывод о единстве временной соотнесенности всего комплекса.

Рассматриваемое интеррогативное высказывание характеризуется также синтаксическим единством: как вопросительное, так и ответные повествовательные предложения являются полными, сложными, с подлежащим уои, которое может указывать как на конкретное, так и на абстрактное лицо. Собирательность местоимения уои, как и вневременной характер настоящего времени глагола, указывает на обобщенность и философский характер проблемы, репрезентированной данным контекстом. Единство семантики выражается в актуализации тем времени и реальности, а также проблемы преодоления жизни, репрезентированных анализируемым 
интеррогативным высказыванием. Связность на уровне микроконтекста достигается посредством использования повтора (уои), контекстуального синонимического повтора (reality - empty space - things; make happen - conjure up, dredge up), антитезы «веселье, забвение - труд, здравость» (conjure up, risks, merry, forget, drink - dredge up, sober mind, toil), «реальность - сказка» (reality - story, tale). Помимо внутреннего единства анализируемого интеррогативного высказывания необходимо отметить его вписанность в макроконтекст главы и всего романа в целом. Так, микротема сказочности, представленная в данном случае антитезой reality - story, формирует центральную тему главы «About the Story-telling Animal», в которой человеческая способность к рассказыванию, повествованию рассматривается не только как возможность заполнить пустоту существования, но и как сущностное свойство человека, отличающее его от животных.

Проблема преодоления реальности является ключевой проблемой всего романа, неотъемлемым компонентом смыслового макропространства произведения. Тема веселья, забвения, со- и противопоставленная теме труда, развивается в дальнейших главах и непосредственно связана с сюжетными линиями семьи Криков и Аткинсонов, истории Фенов. Развернутая метафора, актуализирующая непосредственную роль воды в жизни и труде Криков (dredge up a tale, watery toils), вписывает данный микроконтекст в контекст темы воды и хронотопа Фенов. Таким образом, мы наблюдаем связность не только внутри самого интеррогативного высказывания, которая достигается различными языковыми средствами, но и в пределах мароконтекста произведения.

По степени развернутости ответ в интеррогативных контекстах романа может достигать различных масштабов и формировать часть главы, главу, тему или сюжетную линию. Например, глава «About the Savior of the World», посвященная отношениям Эрнеста Аткинсона и его дочери Хелен, является ответом на вопрос, поставленный повествователем в конце предыдущей главы: Who is my brother? What's he made from? [29, с. 214]. В главе раскрывается как характер отношений между обозначенными выше героями, так и история появления на свет брата рассказчика - Дика Крика. Несмотря на то, что между интеррогативным высказыванием и главой нет прямой связи, тем не менее, она опосредована тематикой главы и системой образов. Кроме того, косвенно ответ на поставленные вопросы дается в названии главы. Так, вопросительное наречие «who» предполагает наличие в ответе лица, деятеля, которым в данном случае является «the savior of the world». В этом выражении актуализируется идея предназначения Дика Крика, окрашенная авторской иронией, возникающей в силу острого противоречия в образе этого героя: с одной стороны, судьбоносность и спасение, с другой стороны, умственная недоразвитость. Рассматриваемое интеррогативное высказывание стимулирует воспоминания и размышления рассказчика, которые формируют всю последующую главу, и акцентирует темы семейной истории, любви, запретной любви, безумия, болезни, смерти, актуальные для всего произведения. Таким образом, мы можем сделать вывод, об образно-ассоциативном виде связи между анализируемым интеррогативным высказыванием и последующей главой, которая может быть интерпретирована как ответ.

Интеррогативные высказывания романа реализуются в различных типах по параметру степени эксплицированности ответа. Например, в ходе анализа были выявлены интеррогативные высказывания с эксплицированным (сжатым и развернутым) ответом, имплицированным ответом и частично эксплицированным ответом. Обратимся к следующему примеру:

Why are the Fens flat? So God has a clear view... [29, c. 21].

Рассматриваемое интеррогативное высказывание демонстрирует образно-ассоциативный вид связи между вопросом и ответом. Фены в романе ассоциируются со сказочной страной, что репрезентировано на глубинном уровне смысловой антитезой «сказка - реальность», а на поверхностном уровне лексикой, в семантику которых входит компонент значения «сказка», «нереальность», и такими предложениями, как A fairy-tale land [29, с. 26]. Следовательно, мы можем проследить неявную, опосредованную связь вопроса и ответа посредством контекстуальной семантики существительных «Fens» и «God». Кроме того, с точки зрения анализа коммуникативной ситуации интеррогативное высказывание репрезентирует диалог между отцом и ребенком, что обусловливает определенный характер ответа - сказочный, не соотносимый с объективной реальностью, с одной стороны, но несущий морально-нравственную коннотацию и, возможно, частично отражающий мировоззрение адресата, с другой. Ситуация общения объясняет и некую алогичность, присущую интеррогативному высказыванию, поскольку вопрос, на первый взгляд, детски-наивный, на самом деле затрагивает проблему причинности, сути вещей, сущностный характер части окружающей действительности, в то время как ответ актуализирует проблему мировосприятия, носящего религиозный характер. Использование приема апосиопезы в ответе указывает на его незавершенность, открытость, возможность дальнейшего рассуждения и развития мысли. Интенция, заложенная в рассматриваемом вопросе, стимулирует как структурно-композиционное, так и смысловое развитие романа.

Важную роль в формировании глубинного уровня ро- 
мана играют интеррогативные высказывания, в которых ответ формально не представлен. Обратимся к примеру:

And who would choose dredging for their calling? Who would opt this endless and stationary war against mud? $[29$, c. 342]

В рассматриваемом интеррогативном высказывании эксплицирована только вопросительная часть, в которой представлен параллельный вид связи. На языковом уровне связность на уровне микроконтекста достигается посредством приема анафоры, подчёркивающей усиленность и проблемность вопрошания, синонимов («choose» - «opt»), использования развернутой метафоры «dredging - endless and stationary war against mud», которая также служит образному представлению характера описываемой деятельности и выражению субъективного и эмоционально-оценочного отношения к ней. Несмотря на то, что ответ в исследуемом интеррогативном высказывании формально не представлен, он угадывается из более крупного контекста, а именно самой главы «About the Rosa Il», посвященной смерти одного из героев Дика Крика. В главе проводятся аналогии между характером работы по очищению дна реки и характером Дика, образом Дика и образом корабля-экскаватора, на котором он работает, сам эпизод самоубийства Дика связан с водой и этим кораблем. Кроме того, в макроконтексте всего романа раскрываются черты характера героя, его внутренние противоречия, которые наиболее ярко выступают в заключительной главе. Так, вне понимания контекста главы и произведения в целом невозможно угадать, какой ответ предполагает рассматриваемое интеррогативное высказывание. Более того, оно актуализирует темы смерти, воды, преодоления, тяжелого труда, являющиеся центральными для всего романа.

В интеррогативных высказываниях романа не только ответные, но и вопросительные комплексы характеризуются различной степенью развернутости, что также способствует связности текста. По параметру степени эксплицированности вопросительные комплексы внутри интеррогативного высказывания варьируются от частично эксплицированных до максимально распространенных, синтаксически осложненных вопросительных предложений и их совокупностей. Так, с одной стороны, наблюдается тенденция к формальной неполноте интеррогативных высказываний, которая на поверхностном уровне представлена использованием апосиопезы, эллипса, опущением строевых элементов, парентезой, использованием номинативных предложений и т.д. Частично эксплицированные интеррогативные высказывания служат актуализации имплицитных смысловых связей как внутри самого микроконтекста, так и в пределах ближайшего контекста и макроконтекста романа в целом. С другой стороны, формальная осложненность интеррогативных высказываний достигается посредством использования рядов однородных членов предложения, вводных конструкций, причастных оборотов, нескольких придаточных предложений внутри сложноподчиненного и т.д. Зачастую встречаются ряды вопросительных предложений, объединенных различными видами связи в синтаксические и смысловые комплексы.

Таким образом, степень эксплицированности и формальной распространенности вопросительного и ответного комплекса внутри интеррогативного высказывания способствуют как внешней, эксплицированной связности текста, так и актуализации его глубинных, смысловых связей. Анализ макроуровня произведения показал, что интеррогативные высказывания служат формированию сюжетно-композиционного уровня романа, являясь одним из средств развития сюжета. Как уже было показано на примерах выше, они стимулируют развитие авторской мысли, предполагают размышление и выведение нового знания, поиск ответа, что приводит к формированию определенных сюжетных линий, глав, способствуют динамике сюжета, акцентируют внимание на уже описанных ранее событиях. Кроме того, интеррогативные высказывания актуализируют тематические, образные, идейно-смысловые повторы на протяжении всего романа, что способствует единству на глубинном уровне текста. Репрезентируя ключевые для произведения темы, образы, сюжетные линии интеррогативные высказывания позволяют осмыслять их с позиции разных аспектов, например, поиска причины, возможности/невозможности, морально-нравственного аспекта и т.д., чем стимулируют авторское осмысление затронутых проблем.

В целом, в данной статье мы постарались проследить роль интеррогативных высказываний в формировании связности художественного текста на материале романа Г. Свифта «Waterland». Это позволяет сделать вывод, что интеррогативное высказывание по определению служит средством связности текста. Во-первых, вопрос с познавательной и коммуникативной точки зрения стимулирует размышления, направленные на выведение знания и поиск ответа. Во-вторых, структура интеррогативного высказывания, включающего комбинацию вопроса и ответа, выраженных эксплицитно, частично эксплицитно или не выраженных в тексте, но подразумевающихся, способствует как внешней, формальной связности, так и внутренней, имплицитной связи на глубинном уровне текста. В-третьих, на макроуровне произведения интеррогативные высказывания служат формированию сюжета, глав, тематическому и образному единству. Настойчивость вопрошания, выраженная частотным использованием интеррогативных высказываний в романе, позволяет проследить динамику развития отдельных образов, тематических и смысловых линий. 
ЛИТЕРАТУРА

1. Арнольд И.В. Стилистика. Современный английский язык. М.: Флинта; Наука, 2006. 384 с.

2. Арутюнова Н.Д. Предложение и его смысл. Логико-семантические проблемы. М.: Наука, 1976. 380 с.

3. Викторова Е.Ю. 0 некоторых проявлениях диалогичности в русском научном дискурсе // Филология в XXI веке. Пермь: Пермский государственный национальный исследовательский университет, 2019. С. 57-62.

4. Виноградов В.В. Исследования по русской грамматике. М.: Наука, 1975. 562 с. [электронный ресурс] URL: http://project.phil.spbu.ru/lib/data/ru/ vinogradov/syntax.html

5. Вольвак Н.П. Фактор адресата в публичном аргументирующем дискурсе: автореферат дис. ....канд. филол. наук. М., 2002. [элекстронный ресурс] URL: https://www.dissercat.com/content/faktor-adresata-v-publichnom-argumentiruyushchem-diskurse

6. Гальперин И.Р. Очерки по стилистике английского языка. М.: Издательство литературы на иностранных языках, 1958. [электронный ресурс] URL: https:// topuch.ru/i-r-galeperin-ocherki-po-stilistike-anglijskogo-yazika/index17.html

7. Кобелева М.А. Категория интеррогативности как атрибут научного текста // Вестник Челябинского государственного университета. 2007. № 1. С. 57-61.

8. Кобозева И.М. Лингвистическая семантика. М.: Эдиториал УРСС, 2000. 352 с.

9. Ковтунова И.И. Поэтический синтаксис. М.: Наука, 1986. 205 с.

10. Кожина М.Н., Дускаева Л.Р., Салимовский В.А. Стилистика русского языка. М.: Наука, 2008. 463 с.

11. Логинов А.В. Категория интеррогативности в современном русском языке: автореферат дис. ... докт. филол. наук. Тамбов, 2015. 40 с.

12. Логинов А.В. Лексические средства выражения семантики интеррогативности // Филологические науки. Вопросы теории и практики. 2012 . № 6. C. 82-85.

13. Логинов А.В. Функциональная периферия категории интеррогативности // Филологические науки. Вопросы теории и практики. 2012. № 5. С. 104-108.

14. Мостовая Л.А. Риторический вопрос в группе косвенных речевых актов // Вестник РудН. Серия: Русский и иностранные языки и методика их преподавания. 2009. № 4. С. 39-45.

15. Омаева 3.Я. Синтаксические конструкции экспрессивного типа как средство выражения авторских интенций: на материале художественных произведений В.В. Набокова: автореферат дис. ... канд. филол. наук. М., 2006 [электронный ресурc] URL: https://www.dissercat.com/content/sintaksicheskiekonstruktsii-ekspressivnogo-tipa-kak-sredstvo-vyrazheniya-avtorskikh-intents

16. Пешковский А.М. Русский синтаксис в научном освещении. М.: Языки славянской культуры, 2001. 544 с.

17. Рыжов С.А. Функционально-семантические свойства интеррогативных реплик в динамической модели диалога: автореферат дис. ... канд. филол. наук. Ульяновск, 2003 [электронный ресурс] URL: https://www.dissercat.com/content/funktsionalno-semanticheskie-svoistva-interrogativnykh-replik-vdinamicheskoi-modeli-dialoga/read

18. Серль .Дж.Р. Косвенные речевые акты // Новое в зарубежной лингвистике. Сборник статей. № 17. М.: «Прогресс», 1986. [электронный ресурс] URL: https://classes.ru/grammar/159.new-in-linguistics-17/source/worddocuments/xvii.htm

19. Скребнев Ю.М. Очерк теории стилистики. Горький: Горьковский государственный педагогический институт иностранных языков имени Н.А. ДобролюбоBa, 1975. 175 C.

20. Стилистический энциклопедический словарь русского языка / под ред. М.Н. Кожиной. М.: Флинта, 2011. 695 с.

21. Сычева И.Б. Встречный вопрос и его функционирование в динамике диалога: автореферат дис. ... канд. филол. наук. Орел, 2008. [электронный ресурс] URL: https://dlib.rsl.ru/viewer/01003167152\#?page=1

22. Шведова Н.Ю. Русская грамматика. Т.2: Синтаксис. М.: Наука, 1980. [электронный ресурс] URL: https://scicenter.online/russkiy-yazyik-scicenter/ funktsionalnosemanticheskie-tipyi-voprositelnyi-96649.html

23. Bedggood D. (Re)Constituted Pasts: Postmodern Historicism in the Novels of Graham Swift and Julian Barnes // Acheson J., Ross S. The Contemporary British Novel Since 1980. Edinburgh: Edinburgh University Press, 2005. P. 203-217.

24. Encyclopedia Britannica. [электронный ресурс] URL: https://www.britannica.com/search?query=graham+swift

25. Fonioková Z. History, Storytelling and Narrative Construction of Reality in Graham Swift's «Waterland»// Revue Belge de Philologie et d'Histoire. 2017. Vol. 95. P. 561-574.

26. Landow G. History, His Story, and Stories in Graham Swift's Waterland // Studies in the Literary Imagination. 1990. Vol. 23. P. 197-211.

27. Nicol B. The Cambridge Introduction to Postmodern Fiction. Cambridge: Cambridge University Press, 2009. 221 p.

28. Pesso-Miquel C. From Historiographic Metafictions to Bedtime Stories: The Changing Contours of Graham Swift's Novels // Études Anglaises. 2007. Vol. 60. P. $135-147$.

29. Swift G. Waterland. London: Picador, 2010. 355 p.

(c) Гладкова Катерина Юрьевна (Katerina_G_L@mail.ru).

Журнал «Современная наука: актуальные проблемы теории и практики» 